\title{
ARROBAS, UNIVERSIDAD Y SOCIEDAD
}

\section{ARROBAS, UNIVERSITY AND SOCIETY}

Javier Macías del Campo: Ciencias de la Computación. Universidad de Alcalá de Henares. Madrid (España)

javier.macias@uah.es

\section{CURRÍCULUM VITAE}

Diplomado en Informática de Sistemas por la Universidad de Alcalá de Henares (España) e Ingeniero en Informática por la Universidad Complutense de Madrid (España). Profesor en el Centro Asociado de la UNED en Guadalajara y profesor externo del Máster Pluridisciplinar en Informática de la Universidad de Alcalá de Henares (España). Secretario de la Comisión de Investigación del Hospital Universitario de Guadalajara (España) y Miembro de la "Asociación de Enseñantes Universitarios de la Informática" (AENUI), y de la "Computer Society" del IEEE, y de la "Association for Computing Machinery" (ACM).

\section{RESUMEN}

Existen diferentes tipos de encabezados para un texto, como estimados amigos, o estimado amigo, estimada amiga, entre otros, todos perfectamente válidos en castellano. En la actualidad, la tendencia es la de utilizar ambos géneros cuando nos dirigimos a un auditorio mixto. También el símbolo arroba existe desde hace siglos, pero no fue hasta el pasado siglo XX que empezó a usarse con asuduidad por su empleo en los correos electrónicos. 


\title{
PALABRAS CLAVE
}

Encabezados - Arroba - Usos

\begin{abstract}
There are different types of headers to a text, as dear friends, or dear friend, dear friend, female, among others, all perfectly valid in Castilian. Today, the trend is to use both genders when addressing an audience mixed. Also at sign existed for centuries, but it was not until the late twentieth century that was first used for asuduidad for use in emails.
\end{abstract}

\section{KEY WORDS}

Headers - Arroba - Uses

\section{TEXTO}

Por favor, lean en voz alta cada uno de los siguientes encabezados y piensen unos instantes qué les sugieren:

Estimadas amigas:

Estimados amigos:

Estimados amigos y amigas:

Estimadas amigas y amigos:

Estimado amigo, estimada amiga: 
Mi opinión es la siguiente:

Estimadas amigas. Quien habla se dirige a un auditorio femenino.

Estimados amigos. Quien habla se dirige a un auditorio masculino o mixto.

Estimados amigos y amigas. Quien habla se dirige a un auditorio mixto y quiere guardar corrección política. Dado que primero se refiere al sexo masculino, podría ser que el hablante sea varón, o la mayoría de la audiencia sea masculina o quiera discriminar positivamente a los varones.

Estimadas amigas y amigos. Quien habla se dirige a un auditorio mixto y quiere guardar corrección política. Como primero se refiere al sexo femenino, podría ser que el hablante sea mujer, o la mayoría de la audiencia sea femenina o quiera discriminar positivamente a las mujeres.

Estimado amigo, estimada amiga. Quien habla se dirige a un auditorio mixto, quiere guardar corrección política y además dar un enfoque personalizado a su presentación. No insistimos en ello, pero en este caso también se aplicaría lo anteriormente dicho sobre el sexo del hablante y la audiencia.

Podríamos dar alguna variante más, pero con esto es suficiente para el tema que deseo tratar. Hasta aquí, todo bien; los encabezados anteriores son perfectamente válidos en castellano. Antes de proseguir, destacar que en la actualidad se da la tendencia (innecesaria desde un punto de vista estrictamente gramatical) a utilizar ambos géneros cuando nos dirigimos a un auditorio mixto.

Centrémonos ahora en el lenguaje escrito y el caso de querer utilizar en expresiones como las vistas ambos géneros. Dado que las expresiones con ambos géneros 
resultan tediosas de escribir, podemos recurrir si lo deseamos a dos mecanismos economizadores permitidos por la Real Academia Española, uno basado en la barra y otro en el paréntesis, tal y como se muestra en los siguientes ejemplos:

Estimados/as amigos/as

Estimados(as) amigos(as)

Y llega el momento de hablar del símbolo de la arroba @. Este símbolo, cuyo origen no está totalmente determinado y que se remonta como mínimo al siglo XVI, era poco usado a mediados del siglo XX. La situación empezó a cambiar a finales de los años 70 de dicho siglo, cuando se decidió usar en las direcciones de correo electrónico para separar el nombre del usuario del dominio al que pertenece (la decisión fue razonable, ya que en inglés el símbolo de la arroba se lee como at, que podemos traducir en el caso del correo electrónico como "en"). Todavía hubo que esperar cerca de veinte años para que, con el crecimiento exponencial de Internet, se masificara el uso del correo electrónico y por tanto de la arroba.

La combinación formada por el renacimiento de la arroba y su sensación de modernidad tecnológica, la tendencia a especificar los géneros masculino y femenino en el lenguaje, y el parecido (seguramente casual) del símbolo arroba con una a y una o compuestas, ocasionó que desde hace años empezaran a verse expresiones del tipo:

\section{Estimad@samig@s}

Sin negar la creatividad de su primer autor, esta fórmula presenta varios problemas, entre ellos:

No aporta ninguna ventaja al lenguaje hablado.

Ya existen, como hemos visto, soluciones para economizar en la escritura de este tipo de expresiones. Además, dichos mecanismos son de carácter más amplio, 
permitiendo representar la opcionalidad de una forma mucho más potente, como por ejemplo en la frase El/los día/s pasado/s. Un nuevo mecanismo que sólo aporta una solución parcial y que además necesita de un símbolo hasta ahora no usado en la escritura del español, complica la situación más que mejorarla.

Los programas de correo electrónico, los procesadores de texto y otras aplicaciones reconocen "palabras" que contienen el símbolo @ como direcciones de correo.

"[...] la imposibilidad de aplicar esta fórmula integradora en muchos casos sin dar lugar a graves inconsistencias, como ocurre en Día del niñ@, donde la contracción del sólo es válida para el masculino niño." (Diccionario Panhispánico de Dudas; http:/ / buscon.rae.es/dpdI/SrvltGUIBusDPD?lema=genero\#2).

Teniendo además en cuenta que la Real Academia Española no lo admite, deberíamos asumir que quizás como experimento tuvo su gracia, pero ya es hora de dejarlo morir.

¿Por qué tratar este tema aquí? Seamos conscientes que en el ámbito universitario la fórmula antedicha se ha usado ampliamente, incluso desde nuestro propio Rectorado (por cierto, hace meses les escribí al respecto por una circular donde se había utilizado la arroba, con una respuesta muy positiva por su parte). Toda la Universidad debe concienciarse y desterrar ya esta fórmula, dando ejemplo, como es nuestra obligación, a la Sociedad. Cuanto más se tarde se haga, más difícil será acabar con ella (¿conseguiremos desterrar algún día el maldito "en base a", que tan ampliamente ha arraigado?).

Como complemento, se muestra a continuación el número aproximado de apariciones en Internet de la fórmula estimad@s amig@s y de expresiones relacionadas. Se ha utilizado para las búsquedas Google ${ }^{\mathrm{TM}}$ (consultas realizadas el 20/10/2006). 
Expresión

Estimad@s amig@s

Estimados amigos y amigas

Estimadas amigas y amigos

Total

Estimados amigos/as

Estimados amigos(as)

Estimadas amigas/os

Estimadas amigas(os)

Total

Estimados/as amigos/as

Estimados(as) amigos(as)

Estimadas/os amigas/os

Estimadas(os) amigas(os)

Total

Estimados amigos y estimadas amigas

Estimados amigos, estimadas amigas

Estimadas amigas y estimados amigos

Estimadas amigas, estimados amigos
13.608

Número apariciones

26.600

40.700

10.500

51.200

17.200

29

17.229

13.200

408

206 
Estimados amigos

Estimadas amigas

Total
722.894 (calculado)

10.441 (calculado)

733.335 